\title{
Robotik Uygulamalar İçin Su Üstünde Titreşime Dayalı Hareket Eden Yenilikçi Bir İlerleme Mekanizması
}

\author{
Ahmed Burak Tapan and *Murat Reis \\ Faculty of Engineering, Department of Mechanical Engineering, Bursa Uludag University, Turkey
}

\section{Özet}

$\mathrm{Bu}$ makale robotik uygulamalar için su üzerinde titreşime dayalı hareket eden yenilikçi bir ilerleme mekanizması sunmaktadır. Robotların her biri su üzerinde batmadan durmalarını sağlayan düşük yoğunluklu dikey kanat profiline sahip iki ayaktan ve U şeklinde yay çeliğinden üretilmiş elastik bir çubuktan oluşur. Su üzerinde ilerlemek için U şekilli çubuğun ortasına yerleştirilen basit bir sarkaç ile sistem titreşime zorlanır. Kanat kesitine sahip dikey pozisyonlanmış ayaklar su içerisinde salınım yaptıkça ön ve arka yüzeyler arasında oluşan basınç farkı ile robot ileri yönde hareket eder. Çalışmada farklı titreşim frekanslarının ilerleme hızına ve yer değiştirme maliyetine etkisi deneyler ile incelenmiş ve sonuçlar yorumlanmıştır. Buna ek olarak ön modelin yer değiştirme maliyeti (CoT) literatürdeki bazı robotlar ve canlılarınki ile karşılaştırılmıştır.

Anahtar Kelimeler: titreşim, ilerleme, yüzme, robot, elastik

\begin{abstract}
This paper presents an innovative mechanism for vibration based locomotion on water surface for robotic applications. Each of the robots consists of two legs with a low density vertical wing profile that allows them to stand on water and a $U$-shaped elastic beam made of spring steel. The system is forced to vibrate with a simple pendulum placed in the middle of the U-shaped bar to generate locomotion on the water. As the vertically positioned feet oscillate in the water, the robot moves in the forward direction with the pressure difference between the front and rear surfaces. In this work, the effect of different vibration frequencies on the locomotion velocity and the Cost of Transport (CoT) were investigated experimentally and the results were interpreted and discussed. In addition to these, the Cost of Transport of the preliminary model was compared with that of some robots and creatures in the literature.
\end{abstract}

\section{Giriş}

Günümüz robotlarının pek çoğu oldukça yüksek enerji tüketerek koşma, yürüme, sıçrama ve yüzme gibi hareketleri gerçekleştirebilirken, hayvanlar daha az kontrol girdisi ve enerji kullanarak çok daha karmaşık fakat kararlı hareketler yapabilmektedir. Bunun yanında bacaklı robotlar tekerlekli robotlara göre de oldukça yüksek enerji tüketim değerlerine sahiptir. Bu nedenle, düşük enerji tüketim değerlerine sahip bacaklı robotlar geliştirmek için hayvan hareketinin prensiplerini anlamak önemlidir. Bu konuda yapılan çalışmalar, özellikle hayvanların yürüyüş biçimlerine bağlı olarak yer değiştirme (lokomosyon) esnasında tükettikleri enerjiye odaklanmıştır [1-5]. Robotların ilerleme hareketleri üzerine yapılan çalışmalar esas olarak hayvanların hareketlerinin detaylı bir şekilde incelenmesi ve bu hareketlerin fiziksel modellerinin ortaya konulması şeklinde olmuştur [6]. Farklı ilerleme modellerine sahip robotların gelişimi ile ilgili çalışmalar Calisti ve arkadaşları tarafından yapılan bir makalede ayrıntılı bir şekilde incelenmiş ve bu robotlara ait örnekler verilmiştir [7]. Pasif dinamik yürüme veya koşma hareketi yapabilen robotlar, diğerlerine göre daha az kontrole ihtiyaç duyup ve daha az enerji tüketimi ile hareketlerini gerçekleştirirler.

*Corresponding author: Address: Faculty of Engineering, Department of Mechanical Engineering, Bursa Uludag University, 16000, Bursa TURKEY. E-mail address: reis@uludag.edu.tr, Phone: +902242942001 
$\mathrm{Bu}$ tür robotlar, herhangi bir hareket sağlayıcı motor veya kontrol birimi olmaksızın daha doğal yürüme yapabildikleri için insan ve hayvanların ilerlemeleri için kullanışlı bir model olarak gösterilebilirler [8-10]. Zıplayarak koşma hareketi hayvanlar tarafından özellikle yüksek hızlarda oldukça sık kullanılır. Hayvanlar ayrıca hareket kabiliyetlerini arttırabilmek için vücutlarının sertliğini ve şeklini değiştirmektedirler. Zıplayan robotlar üzerine yapılan çalışmalarda, özellikle zıplama hareketi esnasında sertlik ve şekil değiştirme yetenekleri üzerine araştırmalar yapılmaktadır [11]. Zıplayan robotlar ile ilgili ilk çalışmalar 1980 'lerde MIT Bacak Laboratuvarı'nda (Leg Laboratory) yapılmaya başlanmıştır [12]. Ancak bu çalışmalar sonucu, bacakları üzerinde zıplayan robot sistemleri için iki ve üç boyutlu hareketler sonucu ilerleme gerçekleşse de, pahalıya mal olması, karmaşık yapısı ve aşırı enerji tüketimleri nedeniyle kullanışlı olmamışlardır. Ancak uygun şekilde tasarlanmış elastik uzuvlu bir mekanizma, doğal titreşim davranış1 manipüle edilerek daha düşük yer değiştirme maliyetine sahip bacaklı robotların geliştirilmesine imkân sağlamıştır [13-14].

Robotlarda elastik uzuv kullanımı enerji verimliliği beraberinde bir dizi kontrol güçlüğü problemi getirmektedir. $\mathrm{Bu}$ güçlük elastik uzuvların doğal frekansı ile robotun periyodik ilerleme hareketinin frekansları örtüştürülerek giderilebilmektedir. Bununla ilgili olarak M. Reis ve arkadaşları tarafından titreşim yardımı ile yürüyerek, koşarak, sürünerek ve zıplayarak ilerleyebilen oldukça düşük enerji tüketimine sahip elastik bir ilerleme mekanizması geliştirilmiştir [15-17]. Elastik bir çubuktan ibaret olan ilerleme mekanizması farklı doğal frekans modlarını kullanarak yürüme, koşma, sürünme ve zıplama hareketlerini sadece titreşim frekansı basit bir DC motor ve sarkaç ile kontrol edilerek yapabilmektedir. Son yıllarda elastik uzuvlu pek çok robotik sistem geliştirilmiştir. Örneğin Bhatti ve arkadaşları tek ayaklı bir hidrolik robot için sıçrama yüksekliği, adım uzunluğu ve dolayısı ile uçuş süresini değiştirebilecek basit ama etkili bir kontrol ünitesi geliştirmiştir [18].

$\mathrm{Su}$ altı ve su üstü robotlar da benzer şekilde canlılardan ilham alınarak geliştirilmiştir. Bu sebeple suda yaşayan hayvan hareketlerinin incelenmesi ve fiziksel modellerinin ortaya konulması efektif su robotları geliştirilmesi için ilk adımları oluşturmuştur [19-23]. Suda ilerleme mekanizmaları dört ana gruba ayrilabilir. Bunlardan ilki, mikroskobik canlıların ve mikro-robotların su yüzeyinde ve suya batmadan yaptıkları ilerleme hareketidir [23,24]. İkinci ilerleme şekli ise yapının bir kısmının su içerisinde olduğu, diğer kısmının ise su dışında olduğu ilerleme şeklidir. Gemilerin, kuşların, insanın sudaki ilerlemesi bu şekildedir [19]. Üçüncü ilerleme şekli, su altında ancak su tabanına temas etmeyecek şekilde ilerleme yöntemidir ki; balıklar, denizaltılar ve bazı robotlar bu şekilde ilerler [20]. Dördüncü ilerleme şekli ise su tabanına temas halindeki ilerleme şeklidir. Bu hareket şekli yengeçlerin ve ağır su altı robotlarının ilerleme şeklidir.

Bu çalışmada, basit bir sarkaç tarafından titreşime zorlanan elastik bir mekanizmanın su üzerindeki hidrodinamik ilerlemesi incelenmektedir. İlerlemeye etki eden tasarım değişkenlerini ve etkilerini belirlemek için basit bir fiziksel model geliştirilmiştir. Mekanizmada, omurganın merkezine monte edilmiş bir DC motora, motor tarafında tahrik edilen basit bir sarkaç eklenmiştir. Bu motor, elastik gövdenin doğal titreşim frekansları civarında harekete geçirildiğinde, kanat şeklindeki ayaklar su içerisinde dikey yönde salınım hareketi yapmaktadır. Bu hareket sayesinde ön ve arka yüzeyler arasında oluşan basınç farkı ve sarkacın oluşturduğu merkezkaç kuvvetinin etkisiyle elastik mekanizma periyodik bir ilerleme hareketi yapmaktadır. Bu mekanizmanın kendi kendisini organize ederek gerçekleştirdiği ilerleme, herhangi bir merkezi otoriteye, algısal geri bildirime veya planlanmış bir harekete neden olan harici bir elemana ihtiyaç duymamaktadır. Buna benzer bir hareket şekli Reis ve arkadaşları tarafından enerji verimli kara robotlarında kullanılmıştır [15-17]. Bu çalışma aynı yapının su içerisinde de ilerleyebilmesine olanak sağlayacak şekilde geliştirilmesini amaçlamaktadır. Çalışma şu şekilde yapılandırılmıştır: İlk kısımda, elastik çubuk ve çok düşük yoğunluklu ayaklardan oluşan mekanizmanın genel tasarımı, tasarım parametreleri ve geliştirdiğimiz fiziksel modelin tanıtımı ve yapının rezonans frekansları verilmektedir. İkinci kısımda, deney sonuçları ve bu sonuçların değerlendirilmesi bulunmaktadır. Sonuç bölümde ise mevcut çalışmanın sonuçlarından yola çıkarak gelecekte yapılması planlanan çalışmalardan bahsedilmektedir. 


\section{Materyal ve Metot}

Bu bölümde mekanizmanın dinamik davranışına etki eden tasarım değişkenleri basit bir fiziksek model üzerinde gösterilmiştir. Bu sayede mekanizmanın mekanik yapısı, motor kontrolün kavramsal modelleri ve robotun temel ilerleme dinamiklerini karakterize edebilmek için bazı parametreler tanımlanmış ve şekil üzerinde gösterilmiştir (Şekil 1). Mekanizma, basit bir mikro DC motor (1/90 oranında çevrim oranına sahip plastik bir dişli kutusu), batmaya karşı poliüretan köpükten yapılmış kanat şeklindeki iki duba ayak ve U şeklindeki tek parça yay çeliğinden üretilmiş bir ana gövdeden oluşmaktadır. Robotun fotoğrafı, şematik gösterimi ve basit fiziksek modeli Şekil 1' de verilmiştir. Yay çeliğinden üretilen U şeklindeki elastik çubuk, robotun bacaklarını ve omurgasını oluşturmaktadır. Omurganın merkezine monte edilmiş mikro DC motora küçük bir sarkaç bağlanmıştır. Yarım elips kesite sahip poliüretan ayaklar, robotun $11 \mathrm{gr}$ 'lık kütlesini ayak kesiti $\% 50$ oranda suya batacak şekilde taşımaktadır. Bu oran yarım elips kesitli ayakların boyları ile oynanarak kolayca ayarlanabilmektedir. İlerleyen dönemlerde bu oranın ilerleme performansına etkisinin de incelenmesi planlanmaktadır. Deneyler esnasında kullanılan robot ön modelinin boyutları ve kütleler Tablo 1' de verilmektedir.

Table 1. Ön model boyutları

\begin{tabular}{cc}
\hline Değişken & Boyut \\
\hline$m_{\text {motor }}$ & 2 gr \\
\hline$m_{\mathrm{f}}, m_{\mathrm{h}}$ & $1 \mathrm{gr}, 1 \mathrm{gr}$ \\
\hline$m_{\mathrm{R}}$ & $1 \mathrm{gr}$ \\
\hline$M$ & $11 \mathrm{gr}$ \\
\hline$L_{\mathrm{v}}$ & $130 \mathrm{~mm}$ \\
\hline$L_{\mathrm{s}}$ & $140 \mathrm{~mm}$ \\
\hline$R$ & $30 \mathrm{~mm}$ \\
\hline$E$ & $200 \mathrm{GPa}$ \\
\hline$r_{l}$ & $10 \mathrm{~mm}$ \\
\hline$r_{2}$ & $7 \mathrm{~mm}$ \\
\hline$l_{f}$ & $120 \mathrm{~mm}$ \\
\hline$a$ & $0.75 \mathrm{~mm}$ \\
\hline$b$ & $2.45 \mathrm{~mm}$ \\
\hline
\end{tabular}

Mekanizmanın sistematik bir analizini yapabilmek ve kavramsal bir model oluşturabilmek için şu varsayımlar yapılmıştır; (1) Robotun omurgası ve bacaklarını oluşturan elastik kiriş, Şekil 1(c) 'de gösterildiği gibi rigid çubuklardan ve dönme yaylarından oluşan ayrık bir sistem olarak basitleştirilebilir. (2) Sarkacın, motorun, bacakların ve ayakların kütleleri uygun konumlarda birer tekil kütle olarak temsil edilebilir. (3) Bacak ve omurga arasındaki dönüş, Şekil lc' de görüldüğü gibi lineer bir burulma yayı ve sönümleyici eleman ile temsil edilebilir.

$\mathrm{Bu}$ varsayımlara dayanarak, modelimiz burulma ve doğrusal yay sönümleyici elemanlar aracilığıyla birbirine bağlı üç katı bağlantıdan oluşmaktadır. Bu bağlantılarda üç nokta kütle vardır: Birincisi, aktüatör ve omurga kütleleri omurganın merkezinde yer alan bir nokta kütle, $m_{\text {top }}$, olarak temsil edilir. Diğer iki nokta kütle, $m_{f}$ ve $m_{h}$ ile belirtilen ön ve arka ayak kütlelerini temsil eder. Omurga uzunluğu $L_{h}$ Bağlantı noktalarındaki burulma sertliği ve sönümlenmesi sırası ile $k_{\theta}$ ve $d_{\theta}$ ile tanımlanır. Eliptik ayak kesit yüzeyinin düşey ve yatay yarıçapları sırası ile $r_{l}$ ve $r_{2}$ ile verilmektedir. Dönen $m_{\mathrm{R}}$ kütlesi aktüatöre, Şekil lc' de görüldüğü gibi R uzunluğundaki bir çubukla bağlıdır. Özet olarak, bu model 13 mekanik tasarım 
parametresinden $\left(k_{\theta}, d_{\theta}, L_{v}, L_{h}, r_{l}, r_{2}, m_{f}, m_{h}, \mathrm{~V}_{f}, \mathrm{~V}_{h}, m_{t o p}, R\right.$ ve $\left.m_{\mathrm{R}}\right)$, bir kontrol parametresinden ( $\left.\omega\right)$ ve 9 durum değişkeninden $\left(\theta_{f}, \theta_{h}, \beta\right.$ ve bunların birinci ve ikincil zaman türevleri) oluşmaktadır.

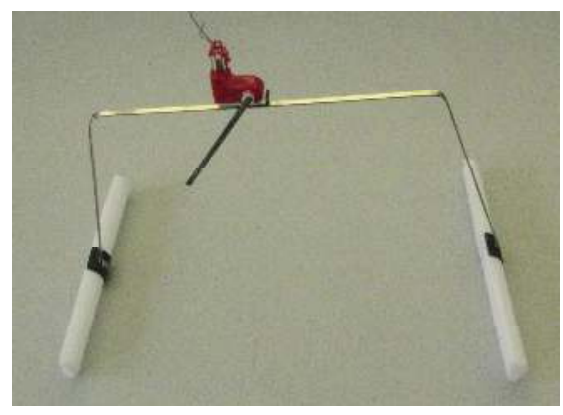

(a)

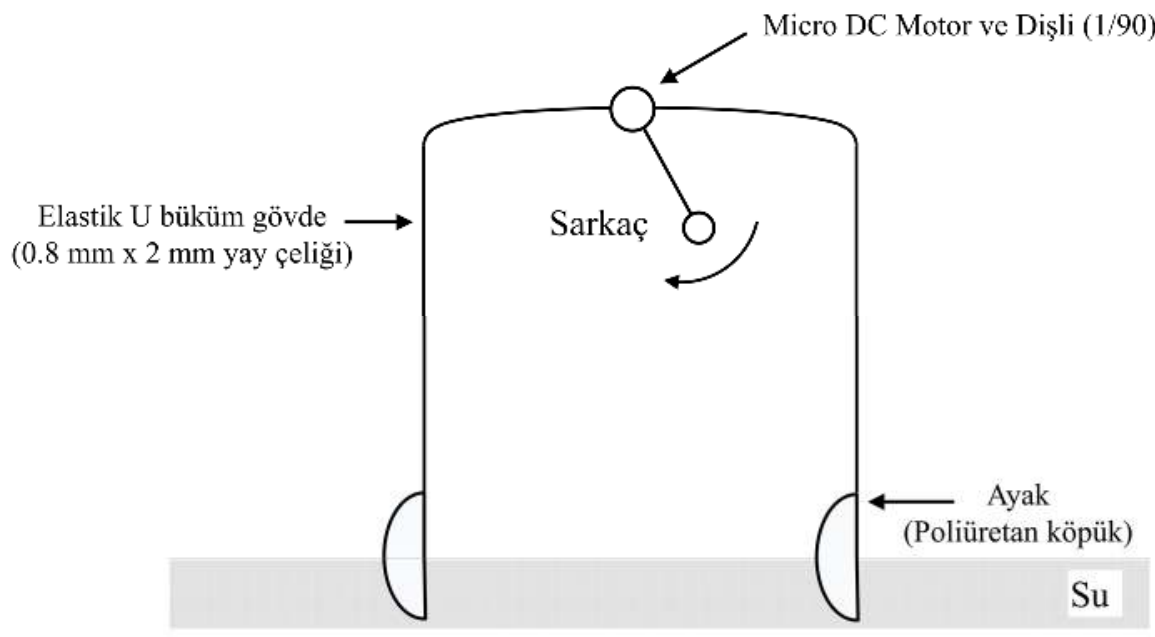

(b)

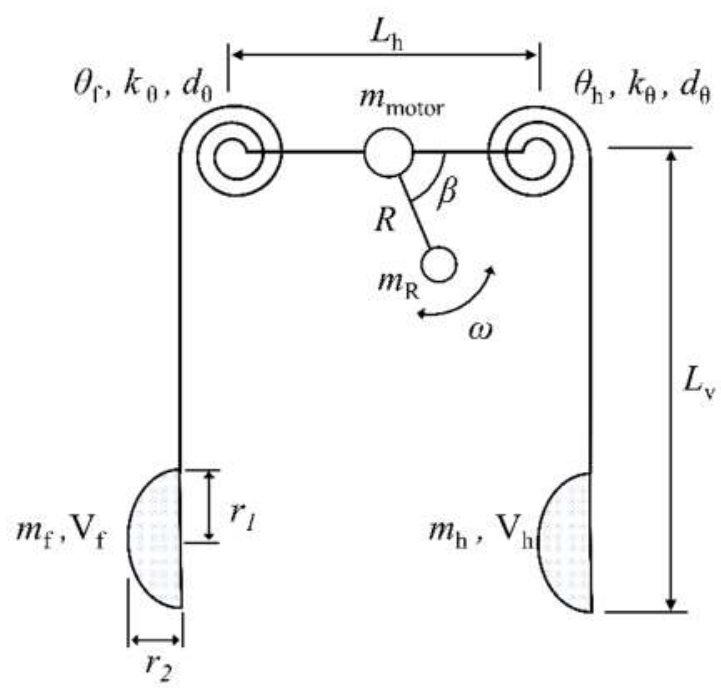

(c)

Şekil 1. Titreşime dayalı su üstünde hareket eden ilerleme mekanizması. (a) Robot fotoğrafi, (b) Robotun şematik gösterimi, (c) Robotun basit fiziksel modeli. 


\section{Deney Sonuçları ve Tartışma}

Titreşime dayalı hareket eden kara robotları [15-17] referans alınarak boyutları belirlenen prototip üzerinde farlı ayak tasarımları denenmiş ve $r_{1}=0.7 \mathrm{~mm}, \mathrm{r}_{2}=10 \mathrm{~mm}$ ölçülerinde yarım elips profiline sahip eliptik bir kanat profili esas alınarak deneyler yapılmıştır. Sarkacın açısal hızı DC motora uygulanan gerilim ile kontrol edilmiş ve aynı anda motor tarafından çekilen akım, enerji tüketimi hesabı için kaydedilmiştir. Robotun hareketi su dolu 70x150 cm boyunda bir akvaryum içerisinde hızlı kamera ile kayıt edilerek sarkacın frekansı hızlı kamera kayıtlarından ölçülmüş̧ür. DC motor gerilimi 0.1 Volt adımlarla artırılarak ölçümler yapılmıştır (1.2 Volt -2.1 Volt).

Şekil 2 'de ilerleme (yüzme) hızının sarkacın açısal hızı ile değişimi görülmektedir. Robot en yüksek yer değiştirme hızına $17.5 \mathrm{rad} / \mathrm{s}$ salınım frekansında sergilemektedir. Bu frekans aralığı çubuğun doğal frekanslarından bir tanesine karşılık gelmektedir. Grafiğin dışında kalan frekans değerlerinde robot kayda değer bir yer değiştirme yapmamaktadır. Şekil 3' te yer değiştirme maliyetinin (Cost of Transport) sarkacın açısal hızı ile değişimi görülmektedir. Bezer şekilde robot en düşük yer değiştirme enerjisi değerlerine 16 $\mathrm{rad} / \mathrm{s}$ ve $17.5 \mathrm{rad} / \mathrm{s}$ değerlerinde ulaşmaktadır. Burada ilerleme hızındaki çok küçük artış ile birlikte DC motora uygulanan gerilimin de yakın oranlarda artması belli bir aralıkta birim kütle başına enerji tüketimini sabit tutmaktadır. Şekil 4 'te çeşitli mekanizmalar ve biyolojik organizmalar için vücut kütlesine göre taşıma maliyetinin değişimi göstermektedir. Tucker diyagramı [25] olarak bilinen bu grafikte çeşitli canlılar ve makinelerin birim kütle başına yer değiştirme maliyetleri boyutsuz birer sayı ile gösterilmektedir. Tüm değerlerin tek bir eğri üzerinde gösterilebilmesi logaritmik bir eğri kullanımını zorunlu kılmaktadır. Mavi yıldız sembolü çalışmada tanıtılan ilerleme mekanizmasının diyagramdaki yerini göstermektedir. Grafikten anlaşılacağı üzere su canlıları yer değiştirmek için en az enerjiye ihtiyaç duyan türdür. Buna karşılık mevcut ilerleme mekanizmasının enerji tüketim değeri oldukça yüksek gözükmektedir. Ancak eğride dikkat edilmesi gereken bir diğer nokta, canlı organizmalar dâhil olmak üzere, tüm türlerde kütle azaldıkça birim kütle başına yer değiştirme enerjisi ihtiyacının hızla arttığıdır. Mevcut robotun daha büyük kütleli versiyonlarında birim kütle başına yer değiştirme enerjisi ihtiyacı yine logaritmik olarak azalacak ve literatürdeki robotların seviyesine inecektir.

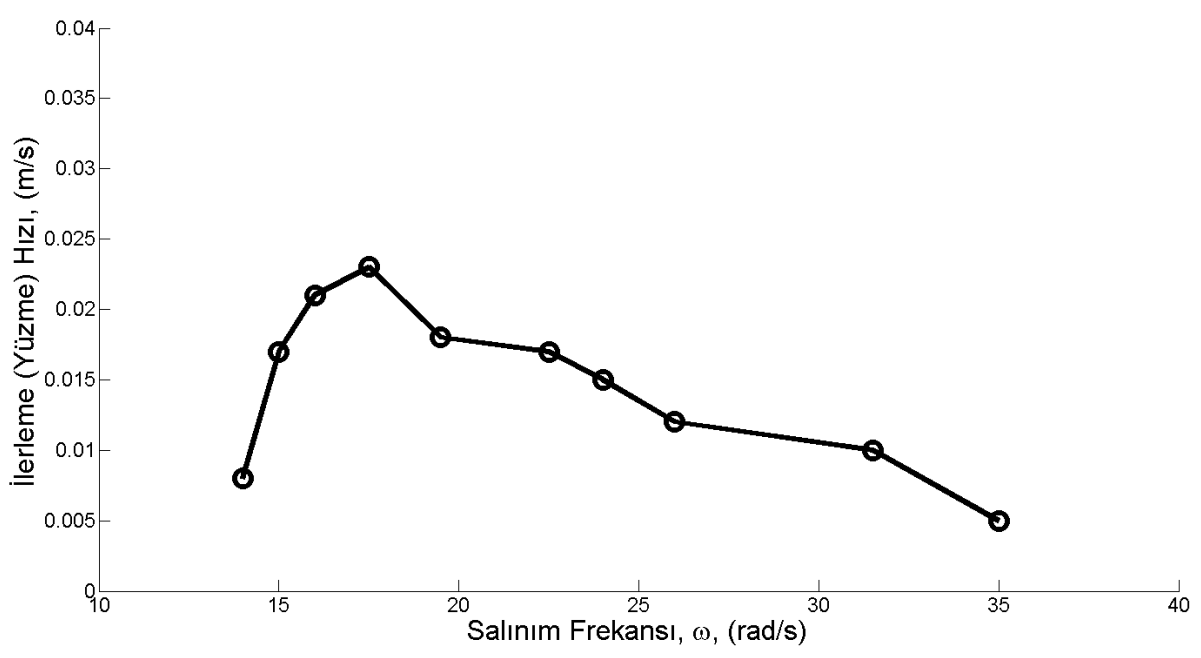

Şekil 2. İlerleme (yüzme) hızının sarkacın açısal hızı ile değişimi 


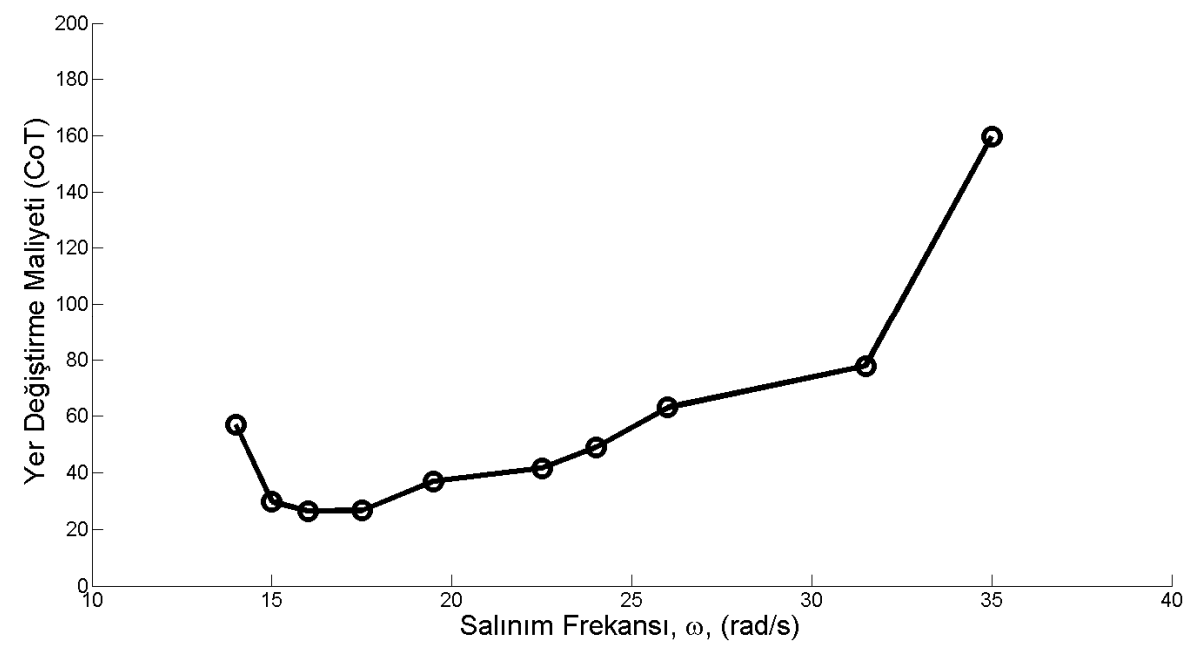

Şekil 3. Yer değiştirme maliyetinin (Cost of Transport) sarkacın açısal hızı ile değişimi

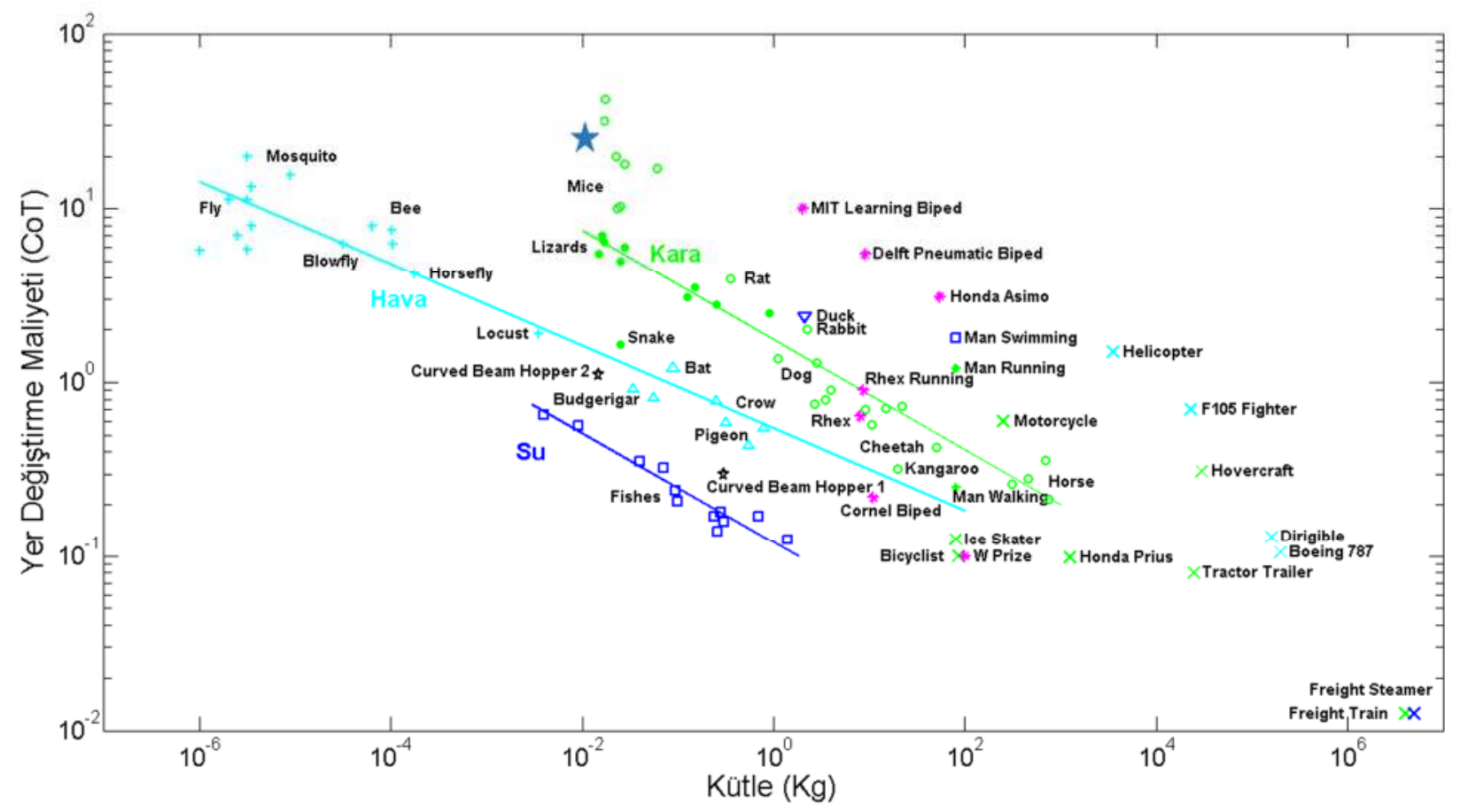

Şekil 4. Çeşitli mekanizmalar ve biyolojik organizmalar için vücut kütlesine göre taşıma maliyeti (Tucker diyagramı, [25]). Mavi yıldız sembolü çalışmada tanıtılan ilerleme mekanizmasının yerini göstermektedir.

\section{Sonuç}

$\mathrm{Bu}$ çalışmada, titreşime zorlanan bir basit bir elastik çubuğun uygun geometri ve ayak yapısı ile suda 
ilerleyebilecek bir mekanizma olarak kullanılabileceği gösterilmiştir. Daha önceki çalışmalarımızda aynı prensipler kullanılarak karada ilerleyen, oldukça düşük enerji tüketimi olan ve farklı salınım frekanslarında farklı ilerleme şekilleri gösteren mekanizmalar tanıtılmıştı. Zira bacaklı robotlar yüksek enerji tüketim değerleri nedeniyle pratikte çok kullanışlı değillerdir. Ancak elastik elemanların ve farklı ilerleme yöntemlerinin geliştirilmesi ile birlikte bu tüketim değerleri biyolojik organizmaların seviyesine yaklaşabilmektedir.

Çalışmanın ilerleyen bölümlerinde suda daha hızlı ilerlemeyi sağlayacak bir ayak yapısının geliştirilmesi hedeflenmektedir. Bu sayede yer değiştirme maliyetinin düşürülmesi ve su canlılarının ilerleme maliyetine daha yakın değerlere ulaşılması amaçlanmaktadır. Mevcut ilerleme mekanizması hem karada hem de suda ilerleyebilme yeteneğinin yanı sıra ölçeklenebilirliği sayesinde çok küçük ve çok büyük boyutlarda üretilebilme özelliğine sahiptir. Öyle ki, hidro-statik yüzey gerilimlerinin yardımı ile su yüzeyinde kalabilecek kadar küçük boyutlu robotların üretimi mümkün olmaktadır ve böyle bir robotun ilk örneği laboratuvarımızda üretilmiştir. Ancak suya batmayan bir robotun titreşim ile ilerlemesi için yine farklı bir ayak yapısının geliştirilmesini gerekmektedir. Buna ek olarak miligram ile ölçülen kütlelerdeki bir robota elektrik enerjisinin iletilmesi de oldukça problemlidir. Zira çok ince kablolar kullanıldığında dahi kablolarda oluşan gerilmeler robotun hareketini etkilemekte ve kısıtlamaktadır. Bu problem de ilerleyen çalışmalarda aşılması gereken zorluklardan bir tanesidir.

\section{Appendix}

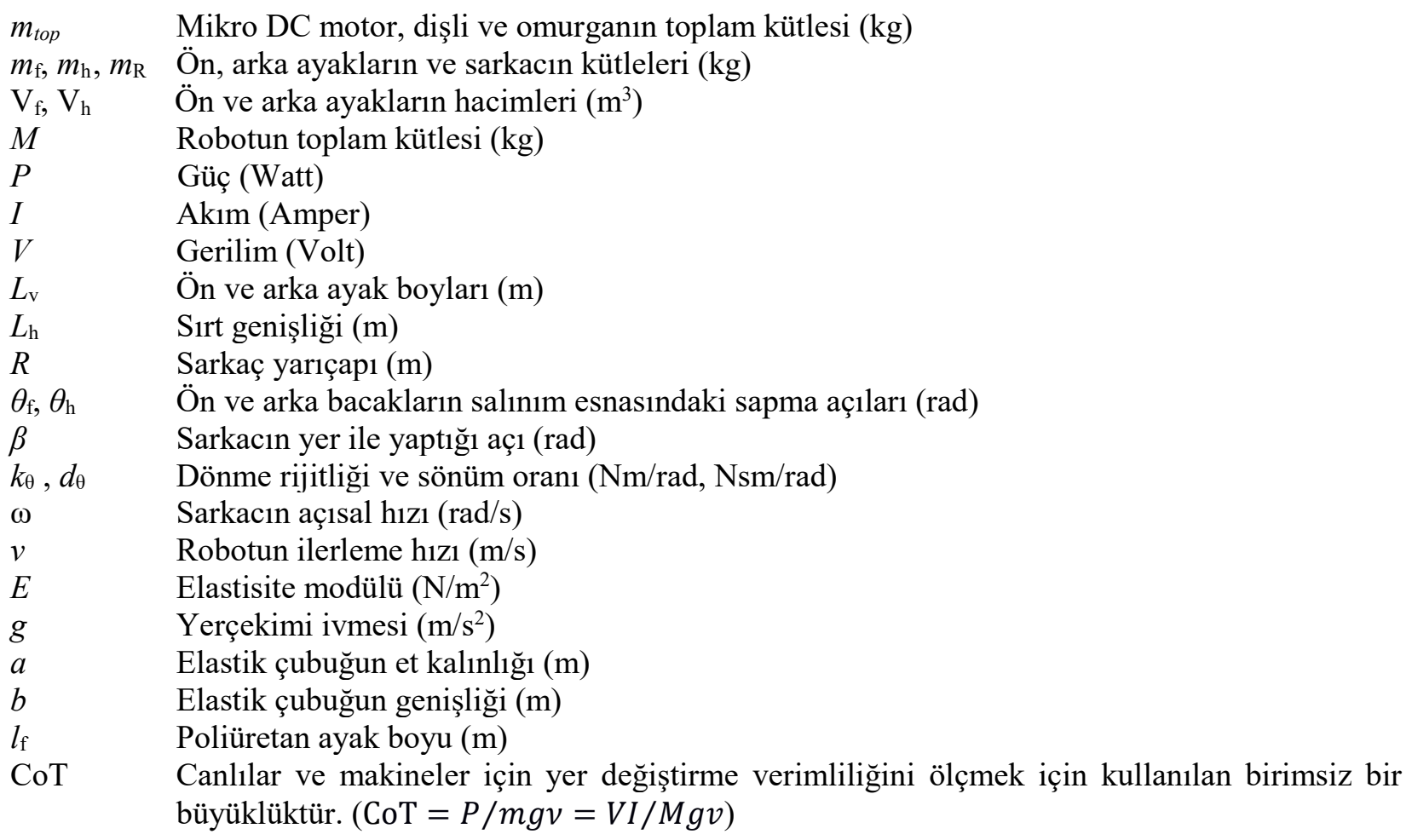

\section{Kaynaklar}

[1] Kar DC, Kurien IK, Jayarajan K. Gaits and energetics in terrestrial legged locomotion. Mechanism and Machine Theory 2003; 38:355-366.

[2] Armour R, Paskins K, Bowyer A, Vincent J, Megill W. Jumping robots: a biomimetic solution to locomotion across rough terrain. Bioinspiration \& Biomimetics 2007; 2:565-582. 
[3] Zhang Z, Chen D, Chen K, Chen H. Analysis and comparison of two jumping leg models for bioinspired locust robot. Journal of Bionic Engineering 2016; 13:558-571.

[4] Hanan U B, Weiss A, Zaitsev V. Jumping efficiency of small creatures and its applicability in robotics. Procedia Manufacturing 2018; 21:243-250.

[5] Kelasidi E, Jesmani M, Pettersen K Y, Gravdahl J T. Locomotion efficiency optimization of biologically inspired snake robots. Applied Science 2018; 8:1-23.

[6] Alexander R N. Principles of animal locomotion. Princeton, NJ: Princeton University Press; 2006.

[7] Calisti M, Picardi G, Laschi C. Fundamentals of soft robot locomotion. Journal of Royal Society Interface 2017; 14:1-16.

[8] McGeer T. Passive dynamic walking. The International Journal of Robotics Research 1990; 9(2):6282.

[9] Collins S, Ruina A, Tedrake R,Wisse M. Efficient bipedal robots based on passive dynamic walkers. Science 2005; 307:1082-1085.

[10] Owaki D, Koyama M, Yamaguchi S, Kubo S, Ishiguro A. A two-dimensional passive dynamic running biped with knees. IEEE International Conference on Robotics and Automation 2010; 5237 5242.

[11] Kühnel DT, Helps T, Rossiter J. Kinematic Analysis of VibroBot: A Soft, Hopping Robot with Stiffness and Shape-Changing Abilities. Frontiers in Robotics AI 2016; 3:60

[12] Raibert MH. Legged robots. Communications of the ACM 1986; 29: 499-514.

[13] Yu X, Iida F. Minimalistic models of an energy-efficient vertical-hopping robot. IEEE Transactions and Industrial Electronics 2014; 61(2):1053-1062

[14] Geyer H, Blickhan R, Seyfarth A. Spring-mass running: simple approximate solution and application. Journal of Theoretical Biology 2005; 232:315-328.

[15] Reis M, Iida F. Vibration based under-actuated bounding mechanism IEEE/ASME International Conference on Advanced Intelligent Mechatronics 2011; 892-897.

[16] Reis M, Yu X, Maheshwari N, Iida F. Morphological computation of multi-gaited robot locomotion based on free vibration. Artificial Life 2013; 19:97-114.

[17] Reis M, Iida F. An energy-efficient hopping robot based on free vibration of a curved beam. IEEE/ASME Trans. Mechatronics 2014; 19:300-311.

[18] Bhatti J, Hale M, Iravani P, Plummer A, Sahinkaya N. Adaptive height controller for an agile hopping robot. Robotics and Autonomous Systems 2017; 98: 126-134.

[19] Kim HG, Lee SH, Lim E, Jeong K, Seo TW. Comparative study of leg mechanisms for fast and stable water-running. International Journal of Precision Engineering and Manufacturing 2016; 17(3):379385.

[20] Scaradozzi D, Palmieri G, Costa D, Antonio Pinelli A.BCF swimming locomotion for autonomous underwater robots: a review and a novel solution to improve control and efficiency. Ocean 
Engineering 2017; 130:437-453.

[21] Kashem S, Sufyan H.A novel design of an aquatic walking robot having webbed feet. International Journal of Automation and Computing 2017; 14(5):576-588.

[22] Kwak B, Bae J. Locomotion of arthropods in aquatic environment and their applications in robotics. Bioinspiration \& Biomimetics 2018; 13 041002:1-26.

[23] Salazar R, Fuentes V, Abdelkefi A. Classification of biological and bioinspired aquatic systems: A review. Ocean Engineering 2018; 148: 75-114.

[24] Kim HY, Amauger J, Jeong HB, Lee DG, Yang E, Jablonski PG.Mechanics of jumping on water. Physical Review Fluids 2017; 2 100505:1-10.

[25] Tucker VA. The Energetic Cost of Moving About: Walking and running are extremely inefficient forms of locomotion. Much greater efficiency is achieved by birds, fish and bicyclists. Am. Sci. 1975; 63-4: 413-419. 